\title{
ARTICLE
}

Molecular targets for therapy

\section{OT-82, a novel anticancer drug candidate that targets the strong dependence of hematological malignancies on NAD biosynthesis}

\author{
Lioubov Korotchkina ${ }^{1}$ - Denis Kazyulkin ${ }^{1}$ - Pavel G. Komarov ${ }^{1}$ - Alex Polinsky ${ }^{1}$. Ekaterina L. Andrianova ${ }^{1}$. \\ Sangeeta Joshi ${ }^{1} \cdot$ Mahima Gupta ${ }^{1}$ - Slavoljub Vujcic ${ }^{1}$ - Eugene Kononov ${ }^{1} \cdot$ llia Toshkov $^{1} \cdot$ Yuan Tian ${ }^{1}$. \\ Peter Krasnov ${ }^{1} \cdot$ Mikhail V. Chernov $^{2} \cdot$ Jean Veith ${ }^{2} \cdot$ Marina P. Antoch ${ }^{2} \cdot$ Shiloh Middlemiss $^{3} \cdot$ Klaartje Somers $^{3}$. \\ Richard B. Lock ${ }^{3}$ Murray D. Norris ${ }^{3,4} \cdot$ Michelle J. Henderson $^{3} \cdot$ Michelle Haber $^{3} \cdot$ Olga B. Chernova $^{1}$. \\ Andrei V. Gudkov ${ }^{2}$
}

Received: 30 May 2019 / Revised: 23 November 2019 / Accepted: 6 December 2019 / Published online: 2 January 2020

(c) The Author(s), under exclusive licence to Springer Nature Limited 2020

\begin{abstract}
Effective treatment of some types of cancer can be achieved by modulating cell lineage-specific rather than tumor-specific targets. We conducted a systematic search for novel agents selectively toxic to cells of hematopoietic origin. Chemical library screenings followed by hit-to-lead optimization identified OT-82, a small molecule with strong efficacy against hematopoietic malignancies including acute myeloblastic and lymphoblastic adult and pediatric leukemias, erythroleukemia, multiple myeloma, and Burkitt's lymphoma in vitro and in mouse xenograft models. OT-82 was also more toxic towards patients-derived leukemic cells versus healthy bone marrow-derived hematopoietic precursors. OT-82 was shown to induce cell death by inhibiting nicotinamide phosphoribosyltransferase (NAMPT), the rate-limiting enzyme in the salvage pathway of NAD synthesis. In mice, optimization of OT-82 dosing and dietary niacin further expanded the compound's therapeutic index. In toxicological studies conducted in mice and nonhuman primates, OT-82 showed no cardiac, neurological or retinal toxicities observed with other NAMPT inhibitors and had no effect on mouse aging or longevity. Hematopoietic and lymphoid organs were identified as the primary targets for dose limiting toxicity of OT-82 in both species. These results reveal strong dependence of neoplastic cells of hematopoietic origin on NAMPT and introduce OT-82 as a promising candidate for the treatment of hematological malignancies.
\end{abstract}

\section{Introduction}

In the United States alone, nearly 60,000 people die from hematopoietic (HP) malignancies such as leukemia, lymphoma, and myeloma annually [1]. Despite some advancements, treatments for many HP malignancies remain

Supplementary information The online version of this article (https:// doi.org/10.1038/s41375-019-0692-5) contains supplementary material, which is available to authorized users.

Andrei V. Gudkov

andrei.gudkov@ roswellpark.org

Oncotartis, Inc., Buffalo, NY, USA

2 Roswell Park Comprehensive Cancer Center, Buffalo, NY, USA

3 Children's Cancer Institute, Sydney, NSW, Australia

4 University of New South Wales Centre for Childhood Cancer Research, Sydney, NSW, Australia insufficiently efficacious and associated with high toxicity. In addition to acute toxicities, genotoxic treatments have longterm negative effects on health and quality of life, including an increased risk for development of secondary cancers [2]. Therefore, new therapies with improved efficacy and safety are urgently needed.

Some effective anticancer agents are directed against tissue-specific targets rather than cancer-specific targets. For example, $L$-asparaginase- and CD20-targeting drugs $[3,4]$ are widely used in hematological oncology and are considered "anti-tissue/lineage" agents since they do not distinguish between normal and transformed cells and act against lineagespecific metabolic deficiency or lineage-specific surface antigen, respectively. To identify new potential drugs of this type, we screened chemical libraries using a cell-based phenotypic assay for HP tissue-specific cytotoxic agents. A small molecule identified in this screen was found to be an inhibitor of the ubiquitous metabolic enzyme nicotinamide phosphoribosyltransferase (NAMPT). 
NAMPT is the rate-limiting enzyme in the salvage pathway by which nicotinamide adenine dinucleotide (NAD) is synthesized from nicotinamide. NAD can also be synthesized de novo from tryptophan or via an alternative salvage pathway from nicotinic acid (NA) or NA riboside. Since the NAMPT-dependent salvage pathway is the major pathway used in mammalian cells, NAMPT inhibition results in the depletion of NAD, which is essential for energy metabolism, oxidation-reduction reactions, and signaling pathways that regulate gene expression, DNA repair, and calcium homeostasis [5-7]. In general, NAMPT is overexpressed in cancer cells compared with corresponding normal cells, presumably reflecting their heightened metabolic and signaling requirements. In addition, higher NAMPT expression is associated with tumor aggressiveness and poor prognosis [8]. Thus, NAMPT has been defined as an attractive target for anticancer therapy.

Multiple previously identified NAMPT inhibitors have shown efficacy in cancer models, including ovarian, colorectal, HP, prostatic, pancreatic and non-small cell lung carcinomas, neuroblastoma and fibrosarcoma [9-15] (reviewed in [16]). The NAMPT inhibitors FK866, GMX1778 (CHS828) and GMX1778's prodrug, GMX1777, were evaluated in clinical trials in patients with advanced solid tumors, but these did not go beyond Phase II due to serious toxicities, including thrombocytopenia [17, 18]. Nevertheless, targeting of NAMPT remains an attractive strategy that is being explored by multiple drug development teams [16]. Here we describe OT-82, a new NAMPT inhibitor with marked efficacy against HP malignancies, a favorable pharmacological profile and a high therapeutic index.

\section{Methods}

\section{Cell culture and reagents}

Cell lines were obtained from ATCC (Manassas, VA, USA) or Sigma Aldrich (St Louis, MO, USA) and were periodically tested for the lack of mycoplasma contamination. Cells were maintained in RPMI 1640 or DMEM with phenol red supplemented with $10 \%$ fetal bovine serum, 100 units $/ \mathrm{mL}$ penicillin, $100 \mu \mathrm{g} / \mathrm{mL}$ streptomycin, and $2 \mathrm{mM}$ L-glutamine in a humidified atmosphere containing $5 \% \mathrm{CO}_{2}$ at $37^{\circ} \mathrm{C}$. Normal human bone marrow mononuclear cells (BM-MNC) were obtained from ALLCELLS, LLC (Almeda CA, USA). Patients' BM-MNC were procured at the Hematologic Bank of RPCCC and NAMPT monoclonal antibody (clone OMNI 379) was obtained from Cayman Chemicals (Ann Arbor, MI, USA). FK866 was purchased from Selleckchem (Houston, TX, USA). OT-82 has been custom synthesized by Nanosyn Inc (Santa Rosa, CA, USA).

\section{High-throughput screening}

High-throughput screening was performed using $>200,000$ compounds from libraries of synthetic small molecules from Chembridge Corporation (San Diego, CA, USA) and Maybridge Corporation (Altrincham, UK) as described in Supplementary Methods.

\section{Cytotoxicity assay and characterization of cell death}

The effect of compounds on cell viability was assessed by resazurin assay (see Supplementary Methods). Caspase-3 activity was determined using the Caspase Fluorometric (AMC) Substrate/Inhibitor QuantiPak BML-AK005 kit (Enzo Life Sciences, Farmingdale, NY, USA) following the manufacturer's instructions. Two-Step Cell Cycle analysis and Mitochondrial Membrane Potential Assay were performed using a NC-3000 cytometer following the manufacturer's instructions (Chemometec, Gydevang, Denmark; Application note 3001) as described in Supplementary Methods.

\section{Identification and validation of the molecular target of OT-82}

NAMPT was identified as the protein target of OT-82 by affinity chromatography followed by mass spectroscopy (see Supplementary Methods). NAMPT activity was measured using the Cyclex NAMPT Colorimetric Assay Kit (MBL International, Woburn, MA, USA). NAD was measured using Enzyfluo NAD/NADH assay kit (BioAssays Systems, Hayward, CA, USA). ATP was measured using ATPlite Luminescence ATP detection kit (Perkin Elmer, Waltham, MA, USA). All assays were performed following the kit manufacturer's instructions.

\section{Animal studies}

Efficacy studies in mouse models were performed according to protocols approved by the Roswell Park Cancer Institute (RPCI) Institutional Animal Care and Use Committee (IACUC) and the Animal Care and Ethics Committee of the University of New South Wales. Toxicity studies performed in mice and nonhuman primates (Macaca fascicularis) were conducted by Pharmaron (Beijing, China) in accordance with Pharmaron's IACUC policies and procedures.

Studies in mouse subcutaneous and systemic xenograft models are described in the Supplementary Methods. Physiological Frailty Index (PFI) was measured in mice as previously described [19]. 


\section{Statistical analysis}

Data are reported as mean values \pm standard error. For animal studies, mean tumor volume and mean body (or organ) weights were compared between groups using twosided unpaired Student's $t$-test (GraphPad Prism5). In patient-derived xenograft models, event-free survival (EFS) curves were compared between groups by Gehan-Wilcoxon test ( $\mathrm{R}$ statistical software). $p$ values $\leq 0.05$ were considered significant.

\section{Results}

\section{Isolation and optimization of small molecules with specific toxicity towards hematopoietic cancer cells}

To identify the compounds with selective toxicity against HP cancer cells, we performed a cell-based high-throughput screening of more than 200,000 small molecules (Fig. 1a and Supplementary Methods). The three most active compounds (with IC50 values $<1000 \mathrm{nM}$ ) were further characterized using a panel of $12 \mathrm{HP}$ and 17 non-HP cell lines. Compound OT-1901 showed the best combination of activity (IC50 $=$ $26.3 \pm 5.6 \mathrm{nM}$ ) and selectivity (on average, 7.3-fold less toxic to non-HP vs HP cells). A series of 179 proprietary structural analogs of OT-1901 were synthesized and tested for activity and selectivity against HP cancer cells, as well as improved physico-chemical properties. From these, we selected OT-82 (Fig. 1a) as our lead drug candidate.

The spectrum of OT-82 cytotoxicity was determined in vitro using $12 \mathrm{HP}$ cancer and 17 non-HP (breast, prostate, pancreatic, cervical, ovarian, colon and lung carcinomas, melanoma and glioblastoma) human cancer-derived cell lines (Table 1, Fig. 1a, b). The average IC50 for OT-82 was significantly higher in non-HP cancer cells compared with HP cancer cells $(13.03 \pm 2.94 \mathrm{nM}$ vs $2.89 \pm 0.47 \mathrm{nM} ; p<0.008)$ (Table 1; Fig. 1b).
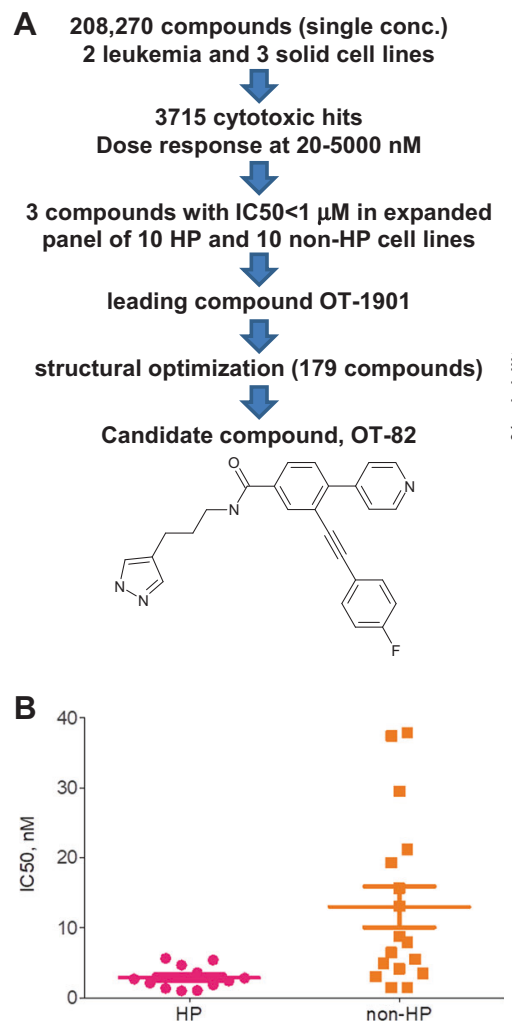

Fig. 1 Identification and characterization of OT-82. a Scheme of OT-82 discovery through a high-throughput, cell-based, phenotypic small molecule screen, followed by hit validation and structure optimization. OT-82 dose dependence of cytotoxicity in HP cell lines (MV4-11, U937, RS4;11, HEL92.1.7, PER485, dashed circle), nonHP cell lines (MCF-7, U87, HT29, H1299, dotted circle) and normal fibroblast cells (WI-39, HFFF2, solid circle). Viability was determined by resazurin staining after $72 \mathrm{~h}$ OT- 82 treatment. b Comparison of the IC50 for OT-82 in cytotoxicity assays performed as in a for multiple

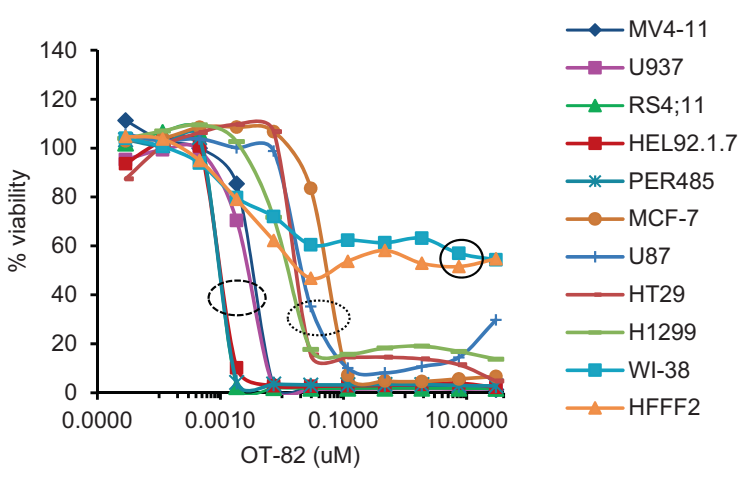

C

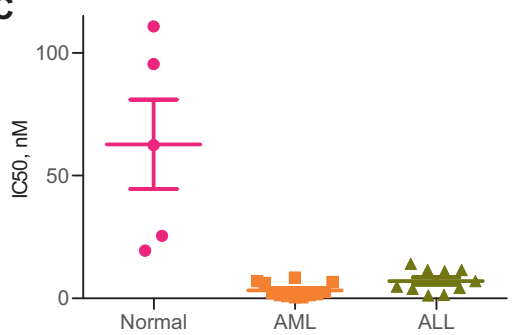

HP and non-HP cancer cell lines. c IC50 for OT-82 in cytotoxicity assays using human total bone marrow cells freshly isolated from adult healthy volunteers $(n=5)$ and AML $(n=12)$, and ALL $(n=10)$ patients. Viability was measured by resazurin staining after $72 \mathrm{~h}$ treatment. $p<0.0001$ for AML patients versus normal and $p=0.0007$ for ALL patients versus normal. b, $\mathbf{c}$ The middle horizontal line indicates the mean value with flanking lines indicating one standard error. 
Table 1 Cytotoxicity of OT-82 towards human cell lines derived from $\mathrm{HP}$ and non-HP cancers.

\begin{tabular}{|c|c|c|}
\hline Name of cell line & Origin & $\mathrm{IC} 50, \mathrm{nM}$ \\
\hline \multicolumn{3}{|c|}{ Hematological malignancies } \\
\hline MV4-11 & AML & $2.11 \pm 0.29$ \\
\hline THP1 & AML & $1.01 \pm 0.35$ \\
\hline PER485 & ALL & $1.36 \pm 0.01$ \\
\hline RS4;11 & ALL & $1.05 \pm 0.16$ \\
\hline CCRF-HSB2 & ALL & $2.41 \pm 0.27$ \\
\hline CCRF-CEM & ALL & $3.61 \pm 0.55$ \\
\hline JURKAT & ALL & $4.68 \pm 1.27$ \\
\hline K652 & CML & $2.82 \pm 0.05$ \\
\hline HEL92.1.7 & Erythroleukemia & $1.86 \pm 0.42$ \\
\hline U937 & Histiocytic lymphoma & $2.70 \pm 0.59$ \\
\hline Raji & Burkitt's lymphoma & $5.64 \pm 1.86$ \\
\hline \multirow[t]{2}{*}{ Ramos } & Burkitt's lymphoma & $5.43 \pm 0.20$ \\
\hline & Average & 2.89 \\
\hline \multicolumn{3}{|c|}{ Non-hematological malignancies } \\
\hline Mel-7 & Melanoma & $5.50 \pm 0.50$ \\
\hline A375 & Melanoma & $4.15 \pm 0.35$ \\
\hline A549 & Lung carcinoma & $3.03 \pm 0.29$ \\
\hline H1299 & Lung carcinoma & $7.95 \pm 0.59$ \\
\hline MCF-7 & Breast carcinoma & $37.92 \pm 4.85$ \\
\hline MDA-MB-231 & Breast carcinoma & $8.78 \pm 2.22$ \\
\hline $22 \mathrm{Rv} 1$ & Prostate carcinoma & $37.46 \pm 0.09$ \\
\hline $\mathrm{C} 4-2$ & Prostate carcinoma & $21.17 \pm 3.39$ \\
\hline PC3 & Prostate carcinoma & $13.13 \pm 2.48$ \\
\hline Du145 & Prostate carcinoma & $6.48 \pm 0.18$ \\
\hline PANC-1 & Pancreatic cancer & $3.53 \pm 0.90$ \\
\hline U87 & Glioblastoma & $29.52 \pm 3.98$ \\
\hline HT29 & Colon carcinoma & $15.67 \pm 8.13$ \\
\hline HCT116 & Colon carcinoma & $1.49 \pm 0.04$ \\
\hline A 2780 & Ovarian cancer & $1.49 \pm 0.20$ \\
\hline HeLa & Cervical cancer & $4.94 \pm 1.15$ \\
\hline \multirow[t]{2}{*}{ HepG2 } & Hepatoma & $19.27 \pm 1.26$ \\
\hline & Average & 13.03 \\
\hline
\end{tabular}

Cell viability was determined by resazurin staining after $72 \mathrm{~h}$ of OT-82 treatment. The data shown are mean \pm SE from 2-10 independent experiments per cell line

$A M L$ acute myeloid leukemia, $A L L$ acute lymphoid leukemia, $C M L$ chronic myeloid leukemia

While OT-82 was cytotoxic towards all types of neoplastic cells tested, the drug had a cytostatic effect on normal diploid fibroblasts (WI-38 and HFFF2 strains), even at concentrations as high as $30 \mu \mathrm{M}$ (Fig. 1a). In addition, BMMNC from healthy donors were significantly less sensitive to OT-82 than BM-MNC from leukemia patients (IC50 = $62.69 \pm 18.20 \mathrm{nM}$ for healthy donors vs $3.31 \pm 0.85 \mathrm{nM}$ for AML and $7.10 \pm 1.47 \mathrm{nM}$ for ALL, $p<0.001$ for both; Fig. 1c). Thus, in vitro, OT-82 demonstrated tissue-selective
(HP vs non-HP) as well as cancer-selective (tumor vs normal) cytotoxicity.

\section{Efficacy of OT-82 in preclinical models of hematologic malignancies}

Next, we tested the therapeutic effect of OT-82 in vivo, using subcutaneous (SC) and systemic mouse xenograft models of HP malignancies. Oral (PO) administration of OT-82 (25 or $50 \mathrm{mg} / \mathrm{kg}$ ) for 6 consecutive days per week for 3 weeks caused dose-dependent suppression of SC growth of human AML-derived MV4-11 cells (Fig. 2a). The 25 $\mathrm{mg} / \mathrm{kg}$ dose led to a threefold reduction in mean tumor volume by day 17 of treatment $\left(385 \mathrm{~mm}^{2}\right.$ vs. $1135 \mathrm{~mm}^{2}, p$ $=0.0001$ ), while the higher dose resulted in complete eradication of tumors within 10 days of treatment initiation with no relapses during 43 days after the discontinuation of treatment. Tumors that grew in the $25 \mathrm{mg} / \mathrm{kg}$ OT-82-treated group grew more slowly than those in the vehicle-treated group and remained sensitive to higher doses of the compound, undergoing near complete regression by day 17 after mice were switched to the $50 \mathrm{mg} / \mathrm{kg}$ dose (Fig. 2a). A similar OT-82 regimen was also effective in a SC xenograft model of human erythroleukemia (HEL92.1.7, Fig. 2b), with $50 \mathrm{mg} / \mathrm{kg}$ dosing reducing mean tumor volume from $961 \mathrm{~mm}^{2}$ (control) to $219 \mathrm{~mm}^{2}$ ( $p=0.0003$ ) by the end of treatment.

OT-82 was also efficacious in systemic leukemia models generated by intravenous (IV) infusion of MV4-11 and HEL92.1.7 cells, with PO administration 6 days/week for 10 weeks significantly prolonging mouse survival (Fig. 2c). In the AML model (MV4-11), 25 and $40 \mathrm{mg} / \mathrm{kg}$ OT-82 dosing increased median survival by 83 days $(161 \%)$ and 87 days $(168 \%)$, respectively $(P<0.0001$ vs control for both), with 30 and $40 \%$ of mice remaining leukemia-free (vs $0 \%$ in vehicle-treated group). For the erythroleukemia model (HEL92.1.7), median survival following $40 \mathrm{mg} / \mathrm{kg}$ OT-82 treatment was extended by 80 days $(233 \%$; $P<$ $0.0001)$.

OT-82 was also highly effective in a patient-derived xenograft model of high-risk pediatric ALL [20-24]. Mice systemically engrafted (IV infusion) with cells from an infant MLL-rearranged ALL patient were treated with $50 \mathrm{mg} / \mathrm{kg}$ OT-82 PO 3 days/week for 6 weeks. OT-82 significantly prolonged EFS of treated mice with a median leukemia growth delay $\left(\mathrm{LGD}=\right.$ median $\mathrm{EFS}_{\text {treated }}$ minus median $\left.\mathrm{EFS}_{\text {control }}\right)$ of more than 57 days $(p<0.0001$; Fig. 2c). According to clinical response criteria (Supplementary Table S1), OT-82 induced a complete response (Supplementary Table S2).

To optimize OT-82 treatment, we varied the duration of consecutive administration and the interval lengths between treatments. Since in vitro studies showed that at least $24-48 \mathrm{~h}$ 

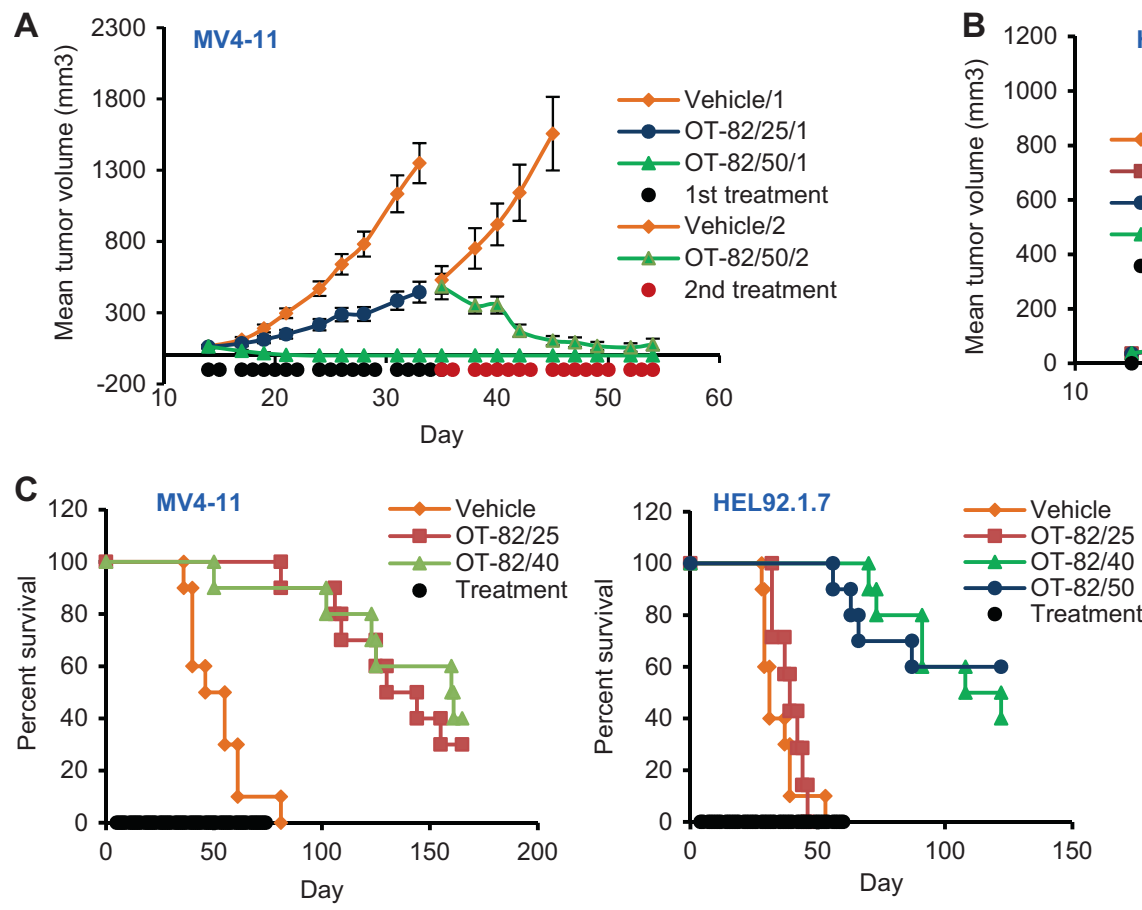
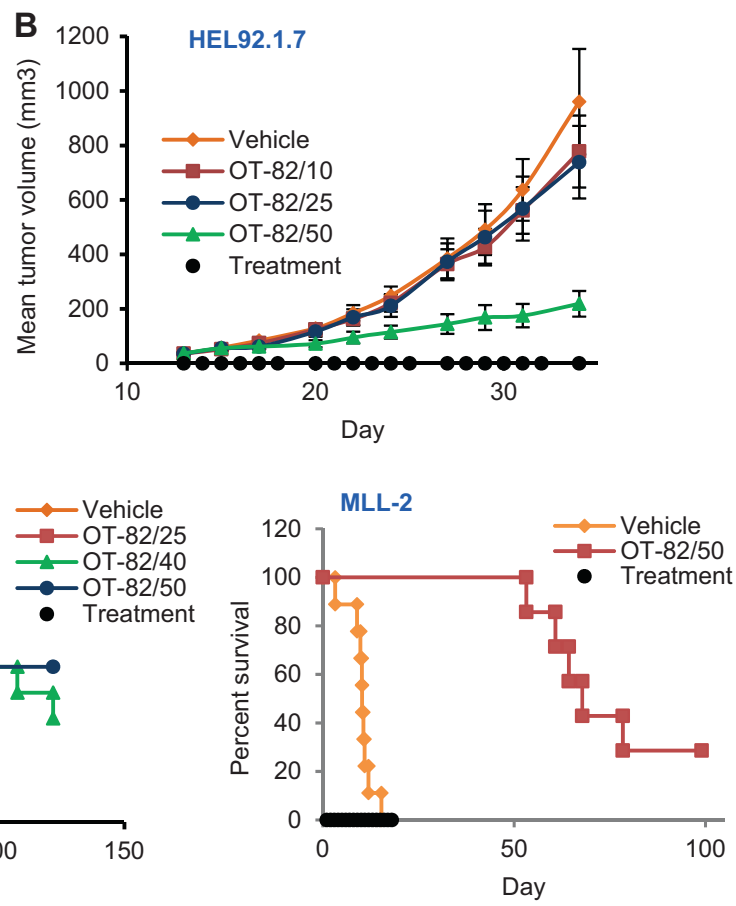

Fig. 2 Efficacy of OT-82 in different xenograft models of hematopoietic malignancies. a OT-82 efficacy in SC xenograft model of MLL-rearranged AML. Mice (SCID) were inoculated SC with $2 \times 10^{6}$ MV4-11 cells on day 0 . Starting on day 14, mice were treated PO with vehicle (30\% HPBCD) or OT-82 (25 or $50 \mathrm{mg} / \mathrm{kg})$ on 6 consecutive days per week for 3 weeks ("1st treatment", days $14-33 ; n=13-15$ mice/group). For secondary treatment, mice treated with $25 \mathrm{mg} / \mathrm{kg}$ on days $14-33$ were divided into two groups ( $n=9-13$ mice/group) and treated with vehicle or $50 \mathrm{mg} / \mathrm{kg}$ OT- 82 according to the same schedule on days 35-54. Mean tumor volume \pm SE is shown and was compared between groups using Students' $t$-test. b OT-82 efficacy in SC xenograft model of erythroleukemia. Mice (SCID) were inoculated SC with $1 \times 10^{6}$ HEL92.1.7 cells on day 0 . Starting on day 13 , mice

of constant incubation with the compound are necessary to detect $>90 \%$ in NAD and ATP depletion (see below), we used 2 days as the minimal period of consecutive treatment. We compared the following regimens applied as three cycles of days of treatment (t)/days of rest (r): 3t/4r; $2 \mathrm{t} / 5 \mathrm{r} ; 3 \mathrm{t} / 7 \mathrm{r}$; and $2 \mathrm{t} / 8 \mathrm{r}$ in SCID mice bearing MV4-11 subcutaneous xenografts (Fig. 3a). All four regimens resulted in the elimination of tumors after three treatment cycles. The $3 \mathrm{t} / 4 \mathrm{r}$ regimen was identified as optimal based on the proportion of mice experiencing relapse within 60 days after treatment discontinuation $(5 \%$ and $20 \%$ in 80 and $60 \mathrm{mg} / \mathrm{kg}$ treatment groups, respectively, vs higher proportions for all other regimens).

Increased efficacy of OT-82 applied using the optimized $3 \mathrm{t} / 4 \mathrm{r}$ regimen was confirmed in the systemic model of AML (MV4-11). With this regimen, $100 \%$ and $56 \%$ of mice treated for 3 weeks with 40 or $20 \mathrm{mg} / \mathrm{kg}$ OT- 82 survived 90 days after treatment discontinuation, respectively (Fig. 3b), as compared with $40 \%$ survival in groups given $40 \mathrm{mg} / \mathrm{kg}$ OT-82 6 days per week $(6 \mathrm{t} / 1 \mathrm{r})$ for 10 weeks were treated PO with vehicle (30\% HPBCD) or OT-82 $(10,25$, or 50 $\mathrm{mg} / \mathrm{kg}$ ) on 6 consecutive days per week for 3 weeks. Mean tumor volume $\pm \mathrm{SE}$ is shown ( $n=14-20$ tumors/group). Differences from the vehicle-treated group were statistically significant $(p<0.05$, Students' $t$-test) for the $50 \mathrm{mg} / \mathrm{kg}$ group from day 20 to 34 (end of the study). c OT-82 efficacy in systemic xenograft models of MLL-rearranged AML (MV4-11), erythroleukemia (HEL92.1.7) and infant MLLrearranged ALL (MLL-2) [24]. Mice were inoculated IV with $10^{7}, 5 \times$ $10^{6}$ and $2.5 \times 10^{6}$ cells, respectively, and treated with the indicated doses of OT-82 PO 6 days per week during the indicated time periods. Treatment was started on day 5 (MV4-11) or day 4 (HEL92.1.7) post inoculation or when the median percentage of huCD $45+$ cells in the peripheral blood of the cohort reached $>1 \%$ (MLL-2).

(Fig. 2c). Notably, improved survival was observed with the optimized regimen even though the total drug exposure was dramatically reduced $(360 \mathrm{mg} / \mathrm{kg}$ for 3 weeks of $3 \mathrm{t} / 4 \mathrm{r}$ $40 \mathrm{mg} / \mathrm{kg}$ dosing vs. $2,400 \mathrm{mg} / \mathrm{kg}$ for 10 weeks of $6 \mathrm{t} / 1 \mathrm{r}$ $40 \mathrm{mg} / \mathrm{kg}$ dosing).

The optimized OT-82 $3 \mathrm{t} / 4 \mathrm{r}$ regimen also potently inhibited tumor growth in SC xenograft models of Burkitt's lymphoma (Fig. 3c) and multiple myeloma (Fig. 3d) and was highly effective in a systemic PDX model of pediatric Philadelphia chromosome-positive $(\mathrm{Ph}+) \mathrm{ALL}$ (Fig. 3e) [20, 22]. In the latter model, OT-82 (40 mg/kg, $3 \mathrm{t} / 4 \mathrm{r}$ ) was more effective (achieved Maintained Complete Response, Supplementary Tables 1 and 2) than a 3-drug standard induction therapy for ALL (vincristine/dexamethasone/ $L$-asparaginase; VXL), which failed to induce a therapeutic response (Objective Response Measure = Progressive Disease 2). Neither of the above-described regimens caused detectable weight loss in treated animals as evident from the graphs presented in Supplementary Fig. S1. 

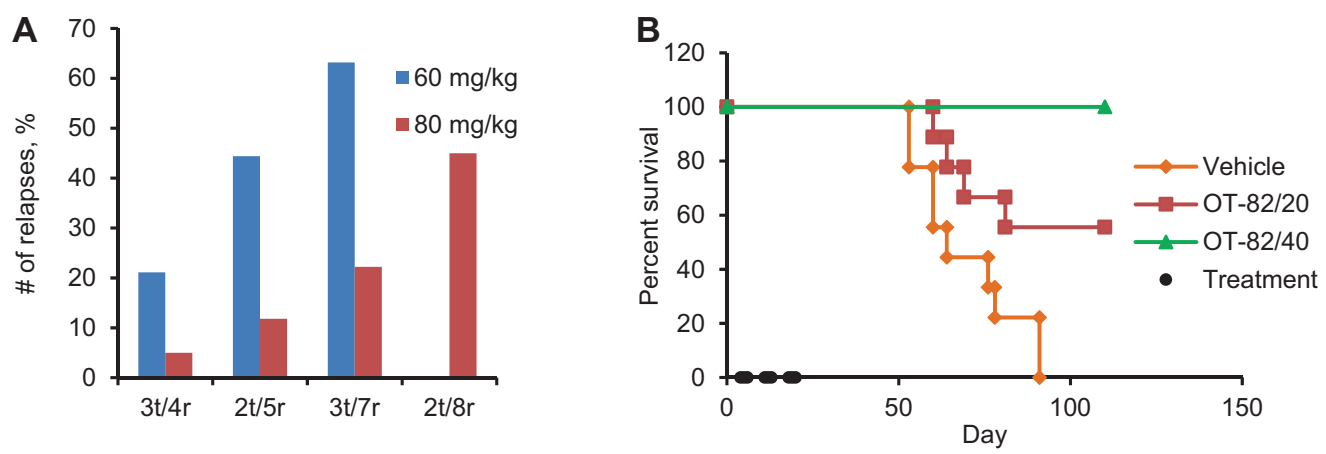
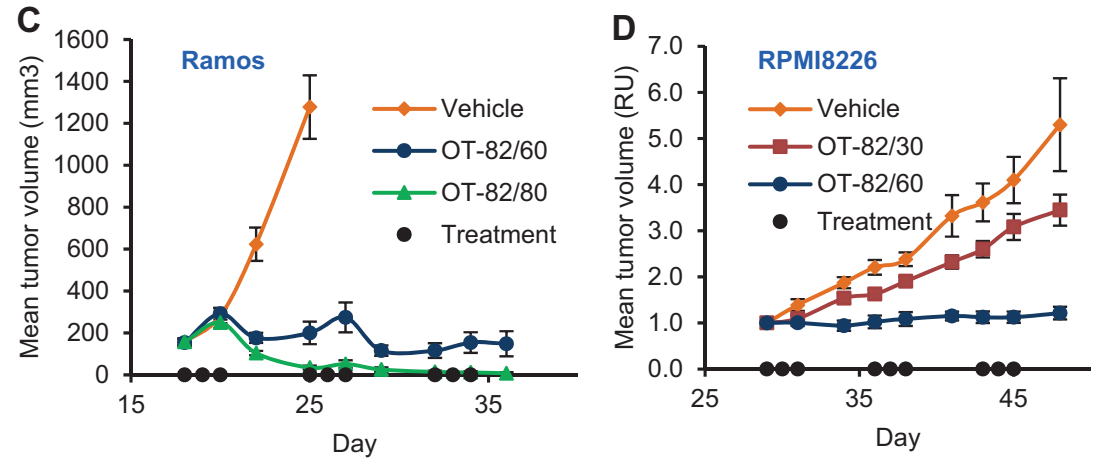

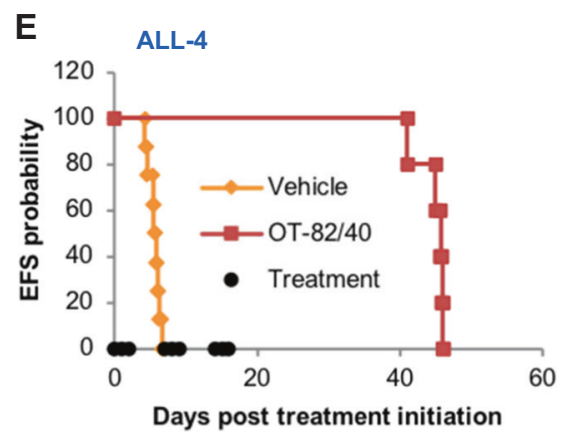

Fig. 3 Optimization of OT-82 treatment regimen in xenograft tumor models. a SCID mice carrying SC MV4-11 tumor xenografts were treated PO with OT-82 (60 or $80 \mathrm{mg} / \mathrm{kg})$ when tumors reached $100 \mathrm{~mm}^{2}$ as follows: 3 days treatment/4 days rest $(3 \mathrm{t} / 4 \mathrm{r}), 2 \mathrm{t} / 5 \mathrm{r}, 3 \mathrm{t} / 7 \mathrm{r}$ or $2 \mathrm{t} / 8 \mathrm{r}$ regimens. $2 \mathrm{t} / 8 \mathrm{r}$ regimen was done only with the dose $80 \mathrm{mg} / \mathrm{kg}$. After three treatment cycles of either regimen, all tumors had disappeared. Treatment was then discontinued, and mice were monitored for relapse for 60 days ( $n=10$ mice/group). b OT-82 optimized regimen efficacy in systemic AML model. Groups of 9-10 SCID mice were inoculated IV with $10^{7} \mathrm{MV} 4-11$ cells on Day 0 and treated PO with vehicle or OT-82 (20 or $40 \mathrm{mg} / \mathrm{kg}$ ) on Days 4-20 following the $3 \mathrm{t} / 4 \mathrm{r}$ regimen for 3 weeks. Mouse survival was monitored for 90 days after treatment discontinuation. c Effect of OT-82 optimized regimen on tumor growth in SC xenograft model of Burkitt's lymphoma. Mice (SCID) were inoculated with $10^{6}$ Ramos cells and treated PO with vehicle or OT-82 (60 or $80 \mathrm{mg} / \mathrm{kg}$ ) 3t/4r for 3 weeks (starting 18 days

\section{Molecular target and mechanism of cytotoxicity of OT-82}

The molecular target of OT-82 was identified as NAMPT by affinity chromatography of MV4-11 cellular extracts exposed to immobilized active OT-82 and an inactive structural analog followed by mass spectrometry and western blotting with anti-NAMPT antibody (Fig. 4a). Functional NAMPT inhibition by OT-82 was confirmed in an in vitro assay using recombinant human NAMPT (Fig. 4a). This showed the IC50 of OT-82 to be similar to that of the well-described NAMPT inhibitor FK866 (41 and 39 nM, respectively) [11].

Further confirmation of NAMPT as the target of OT-82 was provided by utilization of the alternative salvage pathway to synthesize NAD from NA to protect against the toxic effects of NAMPT inhibition: both leukemia cell lines post inoculation). Mean tumor volume $\pm \mathrm{SE}$ is shown $(n=16-20$ tumors/group). $p<0.05$ from Day 22 onwards for both OT-82 treatment groups (Students' $t$-test). d OT-82 optimized regimen efficacy in SC xenograft model of multiple myeloma. Mice (SCID) were inoculated SC with $10^{7}$ RPMI8226 cells and treated PO with vehicle or OT$82(30$ or $60 \mathrm{mg} / \mathrm{kg}$ ) 3t/4r for 3 weeks starting 29 days post inoculation. Mean tumor volume $\pm \mathrm{SE}$ is shown in relative units (RU) compared with initial tumor volume ( $n=12-16$ tumors/group). $p<0.05$ from Day 31 onwards for $60 \mathrm{mg} / \mathrm{kg}$ OT-82 versus vehicle and from Day 34 onwards for $30 \mathrm{mg} / \mathrm{kg}$ OT-82 versus vehicle (Students' $t$-test). e OT-82 optimized regimen efficacy in a systemic PDX model of highrisk ALL (ALL-4) [21]. Mice (SCID-NOD) were inoculated IV with $2.5 \times 10^{6}$ PDX cells. PO treatment ( $3 \mathrm{t} / 4 \mathrm{r}$ regimen for 3 weeks) with vehicle or OT- $82(40 \mathrm{mg} / \mathrm{kg})$ was initiated when the median percentage of huCD45 + cells in the peripheral blood of the cohort reached $1 \%$.

tested were completely protected from OT-82-induced cell death (up to $10 \mathrm{mM}$ OT-82) by addition of $10 \mu \mathrm{M}$ NA to the culture medium (Fig. 4a).

Consistent with the role of NAMPT as a rate-limiting enzyme in the major NAD biosynthesis pathway and the requirement of NAD for ATP production, OT-82 treatment of MV4-11 cells caused dose-dependent reductions in cellular NAD and ATP concentrations (with expected delay) that were consistent with OT-82's IC50 for cell viability (Fig. 4b, Table 1).

In examining the mechanism of OT-82-induced cell death, we found that in vitro treatment of MV4-11 cells with OT-82 for $48 \mathrm{~h}$ resulted in activation of caspase-3, an increase in the proportion of cells with sub-G1 DNA content, and depolarization of the mitochondrial membrane, all hallmarks of apoptotic cell death (Fig. 4b). The OT-82 concentration producing a $50 \%$ relative effect was 

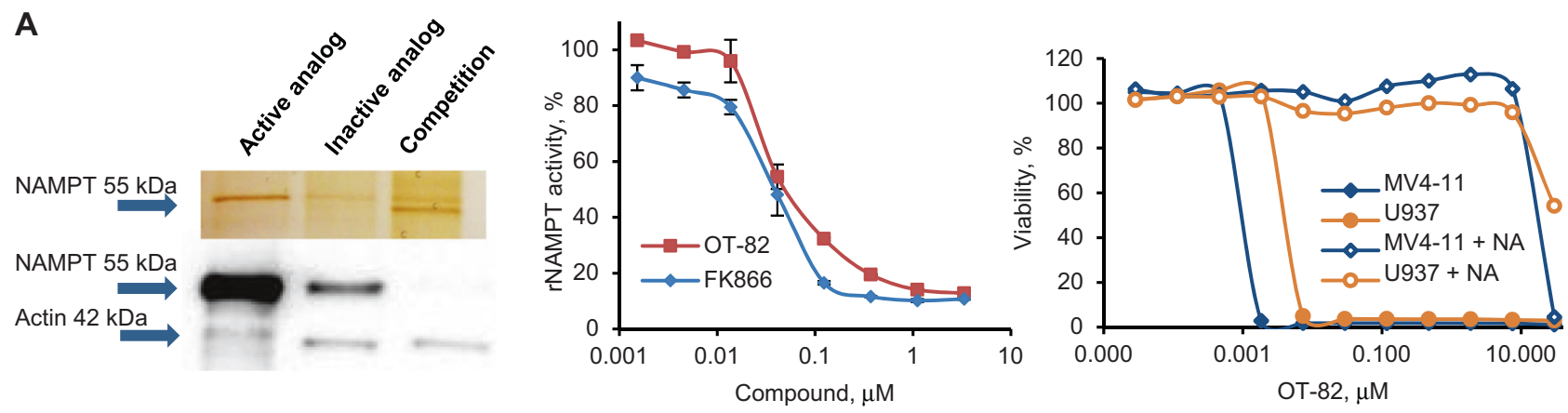

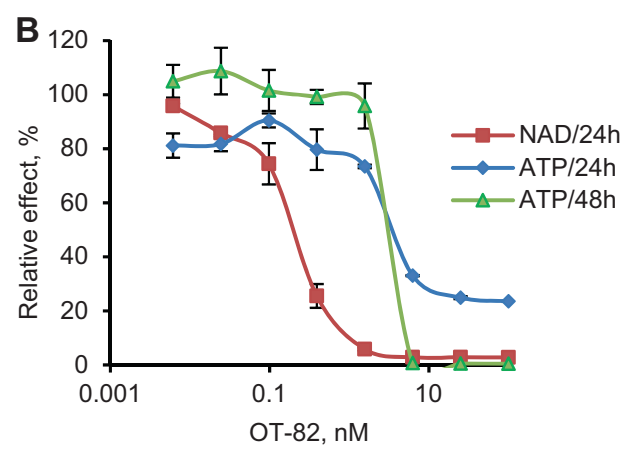

Fig. 4 Identification of NAMPT as a target of OT-82 and the mechanism of OT-82-induced cell death. a Identification of NAMPT as the protein target of OT- 82 by affinity chromatography followed by functional confirmation. MV4-11 cell extract (3 mg protein/reaction) was incubated for $1 \mathrm{~h}$ at $40{ }^{\circ} \mathrm{C}$ with Affi-Gel 10 coupled with "active" compound (OT-82), "inactive" compound (a non-cytotoxic OT82 structural analog), or a combination of the two ("competition"). Eluted proteins were subjected to gel electrophoresis and silver staining (top) or transferred to nitrocellulose membrane for western blotting with NAMPT antisera (bottom). Comparison of inhibitory effects of OT-82 and FK866 on the in vitro activity of recombinant NAMPT indicates close similarity of dose dependence of OT-82 with a bona fide NAMPT inhibitor. Presence of $10 \mu \mathrm{M}$ of nicotinic acid (NA) protects human leukemia-derived cell lines from OT-82-induced

essentially the same in these three assays and was similar to the IC50 for cell viability. Together, these observations indicate that OT-82 induces apoptotic cell death via NAMPT inhibition leading to NAD and ATP depletion.

\section{Effect of dietary niacin on the therapeutic index of OT-82}

Niacin in the form of NA is the substrate for an alternative (NAMPT-independent) salvage pathway for NAD biosynthesis. Given the redundancy of NAD synthesis pathways and the ability of NA to protect leukemia cells from OT-82-induced cell death in vitro (Fig. 4d), we hypothesized that reduced dietary niacin might increase OT-82 efficacy in vivo. To test this, we evaluated OT-82 efficacy in mice fed custom purified Teklad diets (Harlan) containing different percentages $(100,45$, or $15 \%)$ of the recommended daily amount of niacin $(30 \mathrm{mg} / \mathrm{kg}$ [25]) or the regular diet used at RPCI (2018S, Harlan), which contains

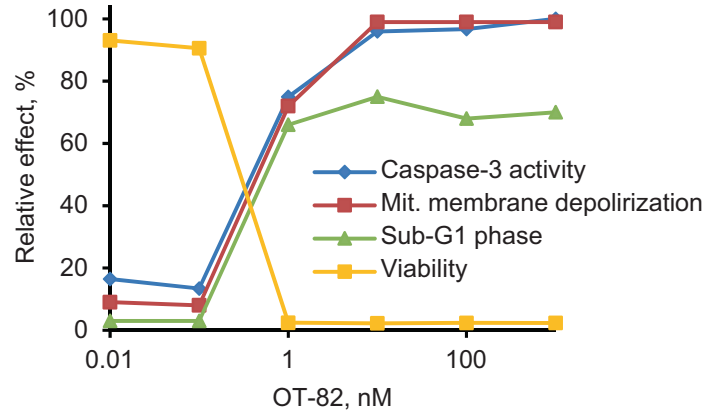

cell death: MV4-11 and U937 cells were incubated with the indicated concentrations of OT-82 in the absence or presence of $10 \mu \mathrm{M}$ NA for $72 \mathrm{~h}$. Viability was measured by resazurin assay. b Characterization of events preceding cell death from OT-82 treatment. Effect of different doses of OT-82 on NAD and ATP concentrations was measured after the indicated time points in MV4-11 cells following OT-82 treatment using Enzyfluo and ATPlite 1 luminescence kits, respectively. Data are shown as relative effect $(\%)$ compared with untreated cells (mean \pm SE; $n=2-3$ ). The right panel indicates the impact of OT- 82 dose on viability and apoptosis markers (activation of caspase-3, depolarization of the mitochondrial membrane, and the proportion of cells with subG1 DNA content) in MV4-11 cells following $48 \mathrm{~h}$ of incubation with different concentrations of OT-82. See Supplementary Methods for details.

$115 \mathrm{mg} / \mathrm{kg}$ niacin $(380 \%$ of the recommended level) (Supplementary Table S3). To determine the ED50 of OT-82 for each diet, SCID mice bearing SC MV4-11 xenografts were treated PO with vehicle or OT-82 $(2-40 \mathrm{mg} / \mathrm{kg}, 3 \mathrm{t} / 4 \mathrm{r}$ for 3 weeks) and tumor growth was monitored as described in the Supplementary Methods. In parallel, the 50\% lethal dose (LD50) was determined by monitoring survival of nontumor bearing SCID mice in the four diet groups treated with OT-82 (25-200 mg/kg, 3t/4r for 3 weeks). Both the ED50 (indicating efficacy) and the LD50 (indicating toxicity) of OT-82 decreased as dietary niacin was reduced. However, diet-dependent reductions in ED50 were greater than those in LD50, resulting in an overall increase in therapeutic index (calculated as LD50/ED50). Consistent with this, $82 \%$ of mice on the regular Harlan diet treated with $40 \mathrm{mg} / \mathrm{kg}$ OT-82 relapsed with tumors within 60 days post treatment, while none or only $17 \%$ of mice in reducedniacin diet groups relapsed (Supplementary Table S3). The inverse relationship between dietary niacin (NA, vitamin 
B3) and anticancer efficacy of OT-82 shown here supports adherence to diets with no more than $100 \%$ of the recommended daily amount of niacin for optimal OT-82 efficacy.

\section{Pharmacological and toxicological profile of 0T-82}

To advance OT-82 towards clinical development, we assessed pharmacological and toxicological characteristics of this drug candidate in mice and nonhuman primates (NHPs, Cynomolgus Monkeys) selected as having similar to human metabolic profiles of OT-82 (see Supplementary Methods and Supplementary Table S4). Recombinant mouse and human NAMPTs in biochemical assays in vitro showed similar their sensitivity to the inhibitory action of OT-82 (Supplementary Fig. S2). Cells derived from both species selected for the toxicological studies showed roughly similar sensitivity to NAMPT inhibitors (Supplementary Fig. S3). The pharmacokinetics and biodistribution of OT-82 after oral administration were evaluated using LC/ MS-MS. The maximum plasma concentrations of OT-82 in mice (dose $10 \mathrm{mg} / \mathrm{kg}$ ) and NHP $(50 \mathrm{mg} / \mathrm{kg}$ ) were 525 and $1049 \mathrm{ng} / \mathrm{ml}$ respectively and were observed at 1 and $3.33 \mathrm{~h}$ respectively with a half-life $\left(T_{1 / 2}\right)$ of about $1.75 \mathrm{~h}$ for both species (Supplementary Table 4). Biodistribution analysis in mice indicated broad bioavailability of OT- 82 with substantial accumulation of OT-82 in all major organs except the brain presumably indicative of inability of the drug to penetrate the blood brain barrier (Supplementary Fig. S4).

Toxicological characteristics of OT-82 in rodents and NHPs were obtained according to Good Laboratory Practice requirements using the projected clinical regimen of administration. Overall, these studies demonstrated good tolerability of OT-82. At a dose $55 \mathrm{mg} / \mathrm{kg}$, which corresponds to the therapeutic dose in multiple mouse models used, no toxicity of the drug has been documented. At the highest doses used $(90 \mathrm{mg} / \mathrm{kg}$ for mice and $30 \mathrm{mg} / \mathrm{kg}$ for NHP) damage in HP and lymphoid organs (bone marrow, spleen, and lymph nodes) with signs of hepatotoxicity were registered in both species. All toxicological effects were reversible, and the measured parameters returned to normal levels within 2 weeks after treatment completion (Supplementary Tables S5 and S6; Supplementary Fig. S5).

Since potential retinal and cardiac toxicities were reported for NAMPT inhibitors GNE-617 and GMX1778 $[16,26,27]$ and NAMPT-mediated NAD + biosynthesis was found to be essential for vision in mice [28], we compared ophthalmological and cardiological effects in C57BL/6 mice of physiologically similar sublethal doses of OT-82 (100 mg/kg) or GMX1778 (125 mg/kg) given PO for 5 consecutive days. While both compounds caused similar body and spleen weight decreases (Fig. 5a, b), only GMX1778-treated animals demonstrated morphological signs of retinal toxicity (reduced thickness of the outer nuclear and outer plexiform layers of the retina, roughness of the external limiting membrane, and numerous pale spaces in the rods and cones layer indicative of cell loss). Consistently, no indications of retinal damage were observed by in-life ophthalmological examination or histopathological assessment of eye tissues in experiments with chronic administration of OT-82 in mice and NHPs.

Potential cardiac toxicity of OT-82 in comparison with GMX1778 was evaluated by histological analysis of H\&Estained sections of heart tissue collected $3 \mathrm{~h}$ after the last drug treatment. Compared with vehicle-treated controls, GMX1778-treated mice showed degenerative changes to the myocardium indicated by local myofibrils degeneration. In contrast, hearts from OT-82-treated mice did not show any type of morphological damage. In NHP studies using implanted telemetry, there were no signs of cardiac toxicity at 10 or $30 \mathrm{mg} / \mathrm{kg}$ OT-82 daily (3 days), with $60 \mathrm{mg} / \mathrm{kg} / \mathrm{day}$ resulting in transient QT prolongation, registered between 2 and $6 \mathrm{~h}$ post the third dosing, with ECG parameters reversed to normal by $8 \mathrm{~h}$. This dose exceeds more than 2 times the dose equivalent planned as the maximal dose for a prospective human phase I study. Thus, unlike previously studied NAMPT inhibitors, OT-82 does not cause retinal or cardiac toxicity within a clinically relevant range of doses.

\section{Effect of OT-82 treatment on frailty index and longevity of mice}

NAD levels have been shown to decline in aging tissues and this decline has been linked to age-related pathologies stemming from malfunctioning of NAD-dependent factors involved in cellular homeostasis (e.g., sirtuins and PARP) [29-31]. Moreover, pharmacological elevation of NAD by increasing dietary niacin was reported to reverse aging biomarkers in mice [32]. This raises a concern that NAMPT inhibitors might accelerate aging and increase the risk of age-related diseases. To address this, we assessed the effect of OT-82 treatment on mouse longevity (natural lifespan) and biological age. Objective quantitative determination of the biological age of animals is possible through a recently developed cumulative health assessment parameter, PFI [19]. As evident from Fig. 6, treatment of aged (87 weeks old) C57BL/6 male and female mice with five courses of OT-82 mimicking the established optimal regimen did not affect longevity or PFI, thus providing additional support for the overall safety of OT-82.

\section{Discussion}

Molecular targets for effective anticancer treatment are typically regulators of proliferation (e.g., RAS or MYC 

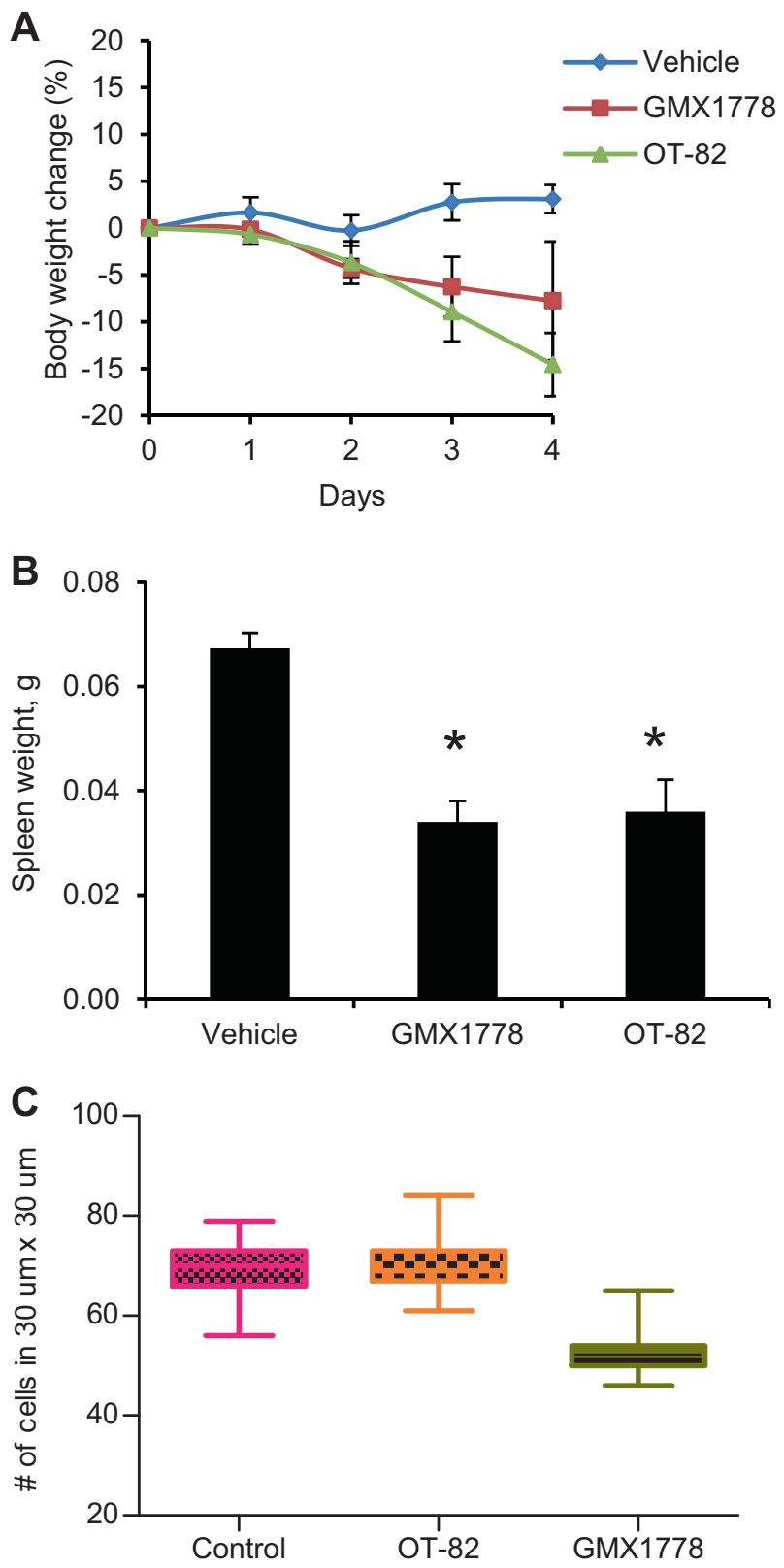

Fig. 5 Comparison of retinal toxicity induced by NAMPT inhibitors GMX1778 and OT-82. C57BL/6 mice were treated PO with vehicle (control), GMX1778 (125 mg/kg), or OT-82 at $(100 \mathrm{mg} / \mathrm{kg})$ for 5 consecutive days. Mice were weighed on each treatment day and organs were collected $3 \mathrm{~h}$ after the last treatment. a Changes in body weight are shown as \% change from baseline weight on the first day of treatment prior to dosing (mean $\pm \mathrm{SE} ; n=3$ mice/group). b Spleen weight after treatment (mean $\pm \mathrm{SE} ; n=3$ mice/group). Asterisks indicate $p$ value $<0.01$. c Cell density in the outer nuclear layer of the retina. Cells in the outer nuclear layer were counted in histological sections (3-5 slides for the left eye and 2-5 slides for the right eye of each mouse; three mice/group). Triplicate counts of nuclei in 3-5 separate $30 \mu \mathrm{m} \times 30 \mu \mathrm{m}$ squares were made for each slide. Mean \pm SE counts were: $69.7 \pm 0.4(n=147)$ for vehicle; $52.8 \pm 0.4(n=102)$ for GMX1778 and $70.0 \pm 0.5(n=90)$ for OT-82. $P<0.0001$ for GMX1778 compared with either vehicle or OT-82. $P=0.54$ for OT82 compared with vehicle. family members, growth factor receptors, etc.) or cell viability (e.g., BCL2 family members, NF-кB pathway regulators, etc.) that are aberrantly expressed in tumors due to structural mutations, amplifications or other types of deregulation and are essential for tumor cell growth or viability [33-35]. Antagonists of such factors can distinguish between normal and transformed cells and thus may have potential as anticancer drugs. However, there are also examples of effective anticancer drugs that do not distinguish between normal and cancer cells, but rather act against tissue-specific targets. Obviously, such drugs can only be directed against tumors originating from tissues that are either not essential for organism viability (e.g., genderspecific tissues) or can be regenerated from intrinsic or transplanted progenitors. The clinical success of this class of "anti-tissue" drugs reflects the failure of tumors to deviate from their epigenetic origin, remaining dependent on tissuespecific factors. Antagonists of androgen and estrogen receptors (e.g., enzalutamide [36, 37] and tamoxifen [38], respectively) used for treatment of prostate and breast cancers, respectively, belong to this category.

Tissue-specific drugs are broadly used in hematologic oncology. These include agents targeting lineage-specific antigens (e.g., anti-CD20 monoclonal antibody rituximab [4] and CD19-targeting CAR T-cell therapies tisagenlecleucel and axicabtagene [39]) or exploiting lineage-specific metabolic deficiencies (e.g., $L$-asparaginase, which blocks supply of the essential amino acid asparagine to myeloid cells deficient in its production [3, 40]). Genotoxic preconditioning by total body irradiation, melphalan, or busulfan (conventionally used in preparation for bone marrow transplantation) is another tissue-specific form of treatment for HP malignancies, capitalizing on the sensitivity of HP cells to DNA damage-mediated apoptosis [41].

NAMPT has been extensively studied as an anticancer target, but without specific focus on HP malignancies [16] except for a recently published demonstration of high sensitivity of MLL-translocated leukemias to NAMPT inhibition [9], an observation that is consistent with our data. NAMPT is not unique in being a tissue-specific target with ubiquitous expression. For example, androgen receptor is expressed in multiple tissues, but its blockade is essentially cytotoxic only for prostate epithelial cells [42]. Hence, tissue-specificity is determined by a target's function rather than its expression. However, there is an important distinction between NAMPT and other tissue-specific targets: in addition to being more critical for the viability of HP versus other cell types, NAMPT inhibition is also more toxic towards malignant versus normal cells of the same HP origin. Thus, NAMPT uniquely combines properties of both tissue specificity and cancer specificity.

Sensitivity of cells to OT-82 did not depend on their proliferation rate (Supplementary Fig. S6) indicating that 


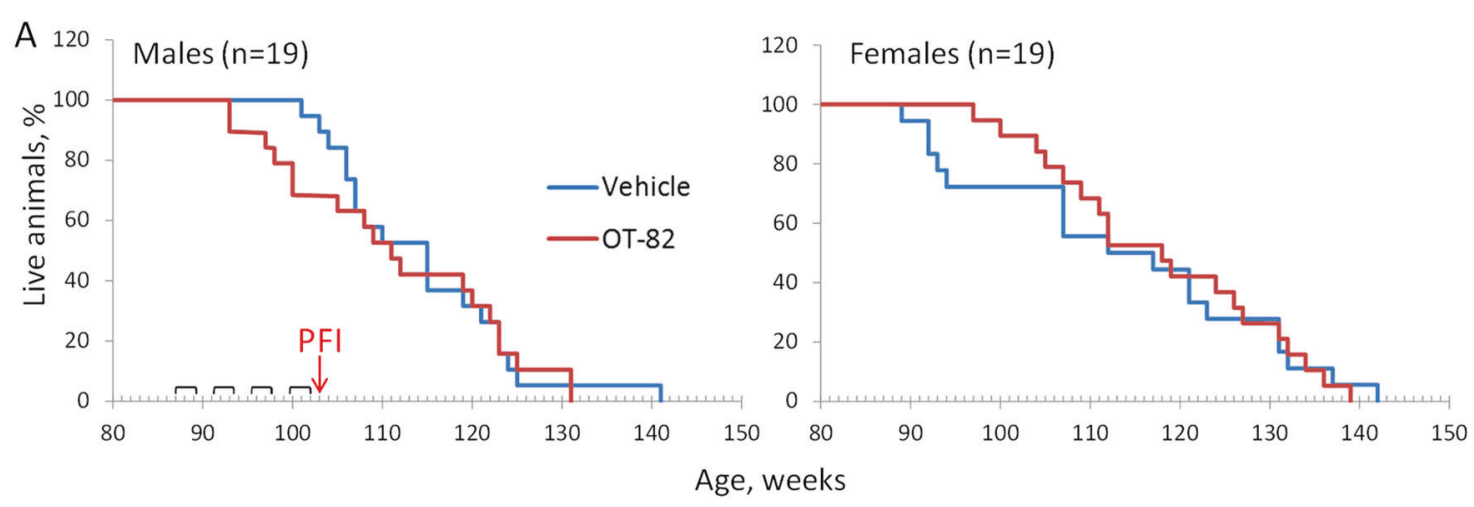

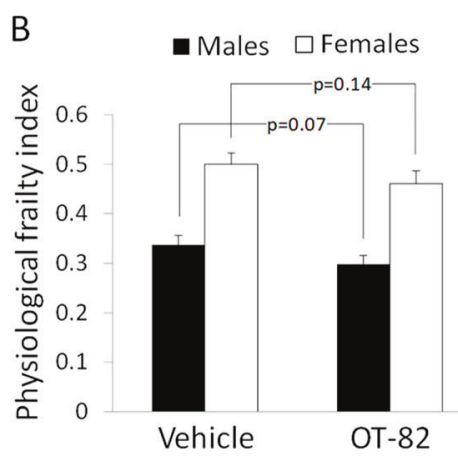

Fig. 6 Treatment with OT-82 does not affect longevity or biological age of mice. a Kaplan-Meier survival curves for male (left panel, $n=19$ ) and female (right panel, $n=19$ ) NIH Swiss mice treated at the indicated times with four cycles of OT-82 or vehicle. Each cycle consisted of 2 consecutive weeks of treatment ( 3 days of daily PO administration of $30 \mathrm{mg} / \mathrm{kg}$ OT- 82 or vehicle followed by 4 days with no treatment); cycles were separated by 2 weeks with no treatment. The first treatment cycle was started when mice were 87 weeks old.

other mechanisms determine selective toxicity of NAMPT inhibition to cancer cells and particularly HP malignancies presumably involving cell type-specific metabolic dependency. Being generally less energy efficient than normal cells [43], tumor cells are expected to be more sensitive to ATP depletion, which unavoidably follows NAMPT suppression. However, OT-82-mediated cytotoxicity showed dependence on the NAD rather than ATP concentration (Fig. 4b) favoring alternative explanations. For example, NAD deficiency affects the function of sirtuins, a class of histone deacetylases [44, 45], and PARP family members that also use NAD as a co-factor [46, 47]. Thus, in addition to causing energy depletion, NAMPT inhibitors combine the activities of two classes of proven anticancer agentshistone deacetylases and PARP inhibitors [45, 47].

Greatly increased sensitivity to NAMPT inhibitors was observed in tumor cells with IDH1/2 mutations known to be associated with reduced baseline levels of NAD) compared with IDH1/2-wild type cells [48]. Thus, mutation of IDH1/2 may represent a predictor of tumor sensitivity to NAMPT inhibitors (IDH1 and IDH2 mutations have been reported in $10-33 \%$ of AMLs, $>80 \%$ of gliomas, $>50 \%$ chondrosarcomas, and $>10 \%$ cholangiocarcinomas [49-51]).

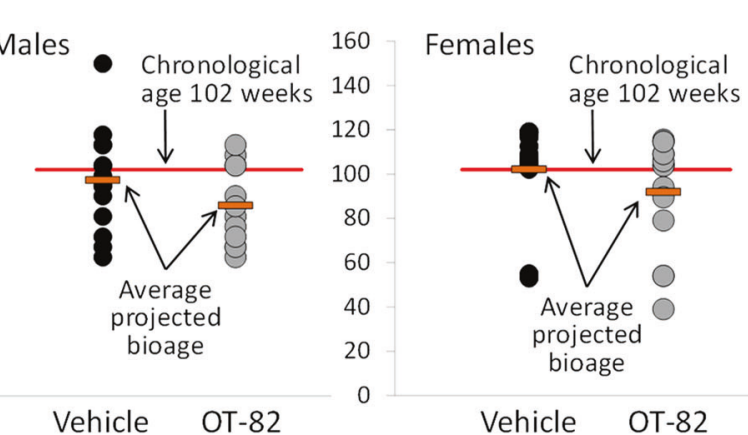

Physiological Frailty Index (PFI) was measured 1 week after the last treatment (at 102 weeks chronological age). b Average Physiological Frailty Index values in the groups of mice described in $\mathbf{a}$ as determined 1 week after the last treatment; $p$ values are shown for comparison of vehicle- and OT-82-treated groups of each gender (two-tailored Student's $t$ test). Error bars indicate SEM. c Comparison of projected "biological ages" of mice from OT-82-treated and vehicle-treated groups calculated based on their PFIs.

IDH1/2-mutant AML is an especially attractive target due to the higher dependency of HP malignant cells on NAD status. While increased sensitivity of cells with IDH1/2 mutations to NAMPT inhibitors has a plausible explanation, the higher susceptibility of HP cells, and particularly transformed HP cells, to NAMPT depletion remains to be explained.

Despite several attempts, no NAMPT inhibitors have been approved as anticancer drugs [18]. Dose limiting toxicities revealed in phase I trials predominantly involved the HP system, which is consistent with the tissue-specific elevated NAMPT dependence described in this study. Clinical trials of previously identified NAMPT inhibitors were mostly conducted in patients with solid tumors [18]. The hematological complications observed in these trials would likely have been more easily handled in patients with HP malignancies in whom these symptoms are common and expected. Furthermore, the treatment schedules used in most published trials are substantially different from the optimal regimen determined in our work (e.g., APO866 was administered by $96 \mathrm{~h}$ intravenous infusion every 4 weeks [17]; CHS828 was administered orally $1 \times$ /week for 4 weeks [18]). By focusing on HP malignancies and optimized regimens, it is highly possible that NAMPT inhibitors could 
show sufficient safety and efficacy to advance in clinical development. Additional opportunities to improve the efficacy of this class of agents include modulation of diet and selection of patients based on tumor IDH1/2 status. Finally, OT-82 represents a structurally new class of NAMPT inhibitors that may avoid some of the pitfalls of its predecessors, as illustrated by the reduced retinal toxicity of OT-82 observed in our experiments, which is likely to reflect lesser ability of OT-82 to penetrate blood-retinal barrier [52] rather than differences in its mechanisms of action from other NAMPT inhibitors. In fact, A2780 cells selected for the resistance to OT-82 were equally resistant to FK866 and vice versa (Supplementary Fig. S7) suggesting similarity in molecular mechanisms of NAMPT inhibition by these otherwise structurally very different compounds.

Overall, our work provides renewed support for the feasibility of pharmacological NAMPT inhibition as an anticancer treatment approach by: (i) describing a new inhibitor with a superior set of properties; (ii) directing clinical development of NAMPT inhibitors specifically towards HP malignancies; (iii) suggesting an effective treatment regimen; and (iv) reducing fears of possible systemic toxicity of NAMPT inhibitors stemming from data showing the importance of NAD levels in aging [53, 54]. In particular, our results indicate the strong clinical potential of OT-82 for safe and effective treatment of hematological malignancies further highlighted in the accompanying manuscript [55].

Acknowledgements This manuscript is dedicated to the memory of Dr Meir Wetzler. We are grateful to Eunice Wang for providing samples from the Hematologic Procurement Bank of Roswell Park Comprehensive Cancer Center. We thank Patricia Stanhope Baker for help in manuscript preparation. This work was supported by grants from Cancer Australia APP1164865 to $\mathrm{MH}, \mathrm{MJH}, \mathrm{KS}$, and $\mathrm{MN}$; from Cancer Council NSW PG16-01 to MJH, MH, MN, and RL; from the National Cancer Institute CA199222 and CA199000, The National Health and Medical Research Council of Australia NHMRC Fellowships APP1059804 and APP1157871, Cancer Australia and Kids' Cancer Project APP1164865, Tenix Foundation and the ISG Foundation to RL and from Anthony Rothe Memorial Trust to RL and MJH; from the National Cancer Institute grant P30CA016056 involving the use of Clinical Data Network and Laboratory Animals Shared Resources to Roswell Park Cancer Center.

Author contributions AVG, OBC, AP, ELA, DK, RBL, MDN, MJH and MH designed the study. LK, DK, PGK, ELA, SJ, MG, SV, EK, IT, YT, PK, MVC, JV, MPA, SM and KS participated in study conduct and data collection. LK, DK, PGK, AP, ELA, IT, PK, MVC, MPA, KS, RBL, MDN, MJH, MH, OBC and AVG analyzed and interpreted the data. LK, ELA, KS, RBL, MDN, MJH, MH, OBC and AVG wrote and/or made critical revisions to the manuscript.

\section{Compliance with ethical standards}

Conflict of interest This work was sponsored by Oncotartis, Inc. (Buffalo, NY, USA). Oncotartis representatives were involved in study design and conduct; data collection, management, analysis, and interpretation; manuscript preparation, review, and approval; and the decision to submit the manuscript for publication. All authors had access to primary study data. LK, DK, PGK, AP, ELA, SJ, MG, SV, EK, IT, YT, PK, MPA, OBC, and AVG were employees or consultants of Oncotartis and received compensation in the form of salary, consulting fees, stock options, or sponsored research.

Publisher's note Springer Nature remains neutral with regard to jurisdictional claims in published maps and institutional affiliations.

\section{References}

1. Siegel RL, Miller KD, Jemal A. Cancer statistics, 2017. CA Cancer J Clin. 2017;67:7-30.

2. Aronson JK. Meyler's Side Effects of Drugs, 16th edn, Elsevier Science, Oxford, UK, 2015.

3. Asselin B, Rizzari C. Asparaginase pharmacokinetics and implications of therapeutic drug monitoring. Leuk Lymphoma. 2015;56:2273-80.

4. Van Meerten T, Hagenbeek A. CD20-targeted therapy: a breakthrough in the treatment of non-Hodgkin's lymphoma. Neth J Med. 2009;67:251-9. p.

5. Galli U, Travelli C, Massarotti A, Fakhfouri G, Rahimian R, Tron GC, et al. Medicinal chemistry of nicotinamide phosphoribosyltransferase (NAMPT) inhibitors. J Med Chem. 2013; 56:6279-96.

6. Chiarugi A, Dölle C, Felici R, Ziegler M. The NAD metabolome - a key determinant of cancer cell biology. Nat Rev Cancer. 2012;12:741-52. p.

7. Bogan KL, Brenner C. Nicotinic acid, nicotinamide, and nicotinamide riboside: a molecular evaluation of NAD + precursor vitamins in human nutrition. Annu Rev Nutr. 2008;28:115-30.

8. Shackelford RE, Mayhall K, Maxwell NM, Kandil E, Coppola D. Nicotinamide phosphoribosyltransferase in malignancy: a review. Genes Cancer. 2013;4:447-56.

9. Matheny CJ, Wei MC, Bassik MC, Donnelly AJ, Kampmann M, Iwasaki M, et al. Next-generation NAMPT inhibitors identified by sequential high-throughput phenotypic chemical and functional genomic screens. Chem Biol. 2013;20:1352-63.

10. Watson M, Roulston A, Belec L, Billot X, Marcellus R, Bedard D, et al. The small molecule GMX1778 is a potent inhibitor of NAD + biosynthesis: strategy for enhanced therapy in nicotinic acid phosphoribosyltransferase 1-deficient tumors. Mol Cell Biol. 2009;29:5872-88.

11. Nahimana A, Attinger A, Aubry D, Greaney P, Ireson C, Thougaard AV, et al. The NAD biosynthesis inhibitor APO866 has potent antitumor activity against hematologic malignancies. Blood. 2009;113:3276-86.

12. O’Brien T, Oeh J, Xiao Y, Liang X, Vanderbilt A, Qin A, et al. Supplementation of nicotinic acid with NAMPT inhibitors results in loss of in vivo efficacy in NAPRT1-deficient tumor models. Neoplasia. 2013;15:1314-29.

13. Xiao Y, Elkins K, Durieux JK, Lee L, Oeh J, Yang LX, et al. Dependence of tumor cell lines and patient-derived tumors on the NAD salvage pathway renders them sensitive to NAMPT inhibition with GNE-618. Neoplasia. 2013;15:1151-60.

14. Fuchs D, Rodriguez A, Eriksson S, Christofferson R, Sundberg C, Azarbayjani F. Metronomic administration of the drug GMX1777, a cellular NAD synthesis inhibitor, results in neuroblastoma regression and vessel maturation without inducing drug resistance. Int J Cancer. 2010;126:2773-89.

15. Chini CCS, Guerrico AMG, Nin V, Camacho-Pereira J, Escande $\mathrm{C}$, Barbosa MT, et al. Targeting of NAD metabolism in pancreatic cancer cells: potential novel therapy for pancreatic tumors. Clin Cancer Res. 2014;20:120-30. 
16. Sampath D, Zabka TS, Misner DL, O'Brien T, Dragovich PS. Inhibition of nicotinamide phosphoribosyltransferase (NAMPT) as a therapeutic strategy in cancer. Pharm Ther. 2015;151:16-31.

17. Holen K, Saltz LB, Hollywood E, Burk K, Hanauske AR. The pharmacokinetics, toxicities, and biologic effects of FK866, a nicotinamide adenine dinucleotide biosynthesis inhibitor. Investig N Drugs. 2008;26:45-51.

18. von Heideman A, Berglund A, Larsson R, Nygren P. Safety and efficacy of NAD depleting cancer drugs: results of a phase I clinical trial of CHS 828 and overview of published data. Cancer Chemother Pharm. 2010;65:1165-72.

19. Antoch MP, Wrobel M, Kuropatwinski KK, Gitlin I, Leonova KI, Toshkov I, et al. Physiological frailty index (PFI): quantitative in-life estimate of individual biological age in mice. Aging. 2017;9:615-26.

20. Szymanska B, Wilczynska-Kalak U, Kang MH, Liem NLM, Carol H, Boehm I, et al. Pharmacokinetic modeling of an induction regimen for in vivo combined testing of novel drugs against pediatric acute lymphoblastic leukemia xenografts. PLoS ONE. 2012;7:e33894.

21. Suryani S, Bracken LS, Harvey RC, Sia KCS, Carol H, Chen I-M, et al. Evaluation of the in vitro and in vivo efficacy of the JAK inhibitor AZD1480 against JAK-mutated acute lymphoblastic leukemia. Mol Cancer Ther. 2015;14:364-74.

22. Liem NLMM, Papa RA, Milross CG, Schmid MA, Tajbakhsh M, Choi S, et al. Characterization of childhood acute lymphoblastic leukemia xenograft models for the preclinical evaluation of new therapies. Blood. 2004;103:3905-14.

23. Lock RB, Liem N, Farnsworth ML, Milross CG, Xue C, Tajbakhsh $\mathrm{M}$, et al. The nonobese diabetic/severe combined immunodeficient (NOD/SCID) mouse model of childhood acute lymphoblastic leukemia reveals intrinsic differences in biologic characteristics at diagnosis and relapse. Blood. 2002;99:4100-8.

24. Houghton PJ, Lock R, Carol H, Morton CL, Phelps D, Gorlick R, et al. Initial testing of the hypoxia-activated prodrug PR-104 by the pediatric preclinical testing program. Pediatr Blood Cancer. 2011;57:443-53.

25. Terakata M, Fukuwatari T, Kadota E, Sano M, Kanai M, Nakamura $\mathrm{T}$, et al. The niacin required for optimum growth can be synthesized from L-tryptophan in growing mice lacking tryptophan-2,3-dioxygenase. J Nutr. 2013;143:1046-51.

26. Zabka TS, Singh J, Dhawan P, Liederer BM, Oeh J, Kauss MA, et al. Retinal toxicity, in vivo and in vitro, associated with inhibition of nicotinamide phosphoribosyltransferase. Toxicol Sci. 2015;144:163-72.

27. Misner DL, Kauss MA, Singh J, Uppal H, Bruening-Wright A, Liederer BM, et al. Cardiotoxicity associated with nicotinamide phosphoribosyltransferase inhibitors in rodents and in rat and human-derived cells lines. Cardiovasc Toxicol. 2017;17:307-18.

28. Lin JB, Kubota S, Ban N, Yoshida M, Santeford A, Sene A, et al. NAMPT-mediated NAD + biosynthesis is essential for vision in mice. Cell Rep. 2016;17:69-85

29. Verdin E. NAD + in aging, metabolism, and neurodegeneration. Science. 2015;350:1208-13.

30. Verdin E. The many faces of Sirtuins: coupling of NAD metabolism, sirtuins and lifespan. Nat Med. 2014;20:25-7.

31. Li J, Bonkowski MS, Moniot S, Zhang D, Hubbard BP, Ling AJY, et al. A conserved NAD + binding pocket that regulates proteinprotein interactions during aging. Science. 2017;355:1312-7.

32. Mills KF, Yoshida S, Stein LR, Grozio A, Kubota S, Sasaki Y, et al. Long-term administration of nicotinamide mononucleotide mitigates age-associated physiological decline in mice. Cell Metab. 2016;24:795-806.

33. Torti D, Trusolino L. Oncogene addiction as a foundational rationale for targeted anti-cancer therapy: promises and perils. EMBO Mol Med. 2011;3:623-36.
34. Pagliarini R, Shao W, Sellers WR. Oncogene addiction: pathways of therapeutic response, resistance, and road maps toward a cure. EMBO Rep. 2015;16:280-96.

35. Willis RE. Targeted cancer therapy: vital oncogenes and a new molecular genetic paradigm for cancer initiation progression and treatment. Int J Mol Sci. 2016;17:1552. p.

36. Helsen C, Van den Broeck T, Voet A, Prekovic S, Van Poppel H, Joniau S, et al. Androgen receptor antagonists for prostate cancer therapy. Endocr Relat Cancer. 2014;21:T105-18.

37. Rathkopf D, Scher HI. Androgen receptor antagonists in castration-resistant prostate cancer. Cancer J. 2013;19:43-9.

38. Martinkovich S, Shah D, Planey SL, Arnott JA. Selective estrogen receptor modulators: tissue specificity and clinical utility. Clin Interv Aging. 2014;6:1437-52.

39. Chow VA, Shadman M, Gopal AK. Translating anti-CD19 CAR T-cell therapy into clinical practice for relapsed/refractory diffuse large B-cell lymphoma. Blood. 2018;132:777-781.

40. Pieters R, Hunger SP, Boos J, Rizzari C, Silverman L, Baruchel A, et al. L-asparaginase treatment in acute lymphoblastic leukemia. Cancer. 2011;117:238-49. p.

41. Gyurkocza B, Sandmaier BM. Conditioning regimens for hematopoietic cell transplantation: one size does not fit all. Blood. 2014;124:344-53.

42. Inoue S, Mizushima T, Miyamoto $H$. Role of the androgen receptor in urothelial cancer. Mol Cell Endocrinol. 2018;465:73-81.

43. Epstein T, Gatenby RA, Brown JS. The Warburg effect as an adaptation of cancer cells to rapid fluctuations in energy demand. PLoS ONE. 2017;12:e185085.

44. Chalkiadaki A, Guarente L. The multifaceted functions of sirtuins in cancer. Nat Rev Cancer. 2015;15:608-24.

45. Hu J, Jing H, Lin H. Sirtuin inhibitors as anticancer agents. Future Med Chem. 2014;6:945-66.

46. Morales J, Li L, Fattah FJ, Dong Y, Bey EA, Patel M, et al. Review of poly (ADP-ribose) polymerase (PARP) mechanisms of action and rationale for targeting in cancer and other diseases. Crit Rev Eukaryot Gene Expr. 2014;24:15-28.

47. Underhill C, Toulmonde M, Bonnefoi H. A review of PARP inhibitors: from bench to bedside. Ann Oncol. 2011;22:268-79.

48. Tateishi K, Wakimoto H, Iafrate AJ, Tanaka S, Loebel F, Lelic N, et al. Extreme vulnerability of IDH1 mutant cancers to NAD+ depletion. Cancer Cell. 2015;28:773-84.

49. Molenaar RJ, Maciejewski JP, Wilmink JW, van Noorden CJF. Wild-type and mutated IDH1/2 enzymes and therapy responses. Oncogene. 2018;37:1949-60.

50. Clark O, Yen K, Mellinghoff IK. Molecular pathways: isocitrate dehydrogenase mutations in cancer. Clin Cancer Res. 2016; 22:1837-42.

51. Marcucci G, Maharry K, Wu YZ, Radmacher MD, Mrózek K, Margeson D, et al. IDH1 and IDH2 gene mutations identify novel molecular subsets within de novo cytogenetically normal acute myeloid leukemia: a cancer and leukemia group B study. J Clin Oncol. 2010;28:2348-55.

52. Hosoya K, Tomi M, Tachikawa M. Strategies for therapy of retinal diseases using systemic drug delivery: relevance of transporters at the blood-retinal barrier. Expert Opin Drug Deliv. 2011;8:1571-87.

53. Chini CCS, Tarragó MG, Chini EN. NAD and the aging process: role in life, death and everything in between. Mol Cell Endocrinol. 2017;455:62-74

54. Imai S, Guarente L. NAD+ and sirtuins in aging and disease. Trends Cell Biol. 2014;24:464-71.

55. Somers K, Evans K, Cheung L, Karsa M, Pritchard T, Kosciolek A, et al. Effective targeting of NAMPT in patient-derived xenograft models of high-risk pediatric acute lymphoblastic leukemia. Leukemia. (2019). https://doi.org/10.1038/s41375-019-0683-6. 